\title{
A Business Case Framework for Planning Clinical Nurse Specialist-led Interventions
}

In Press. A Business Case Framework for Planning Clinical Nurse Specialist-led Interventions. Clinical Nurse Specialist: The International Journal of Advanced Practice Nursing

Rebecca J. Bartlett Ellis, PhD, RN, Assistant Professor, Department Science of Nursing Care Indiana University School of Nursing; 1111 Middle Drive, E423; Indianapolis, Indiana 46202, Office: 317-274-0047; Email: ribartle@iu.edu

Jennifer L. Embree DNP, RN, NE-BC, CCNS, Clinical Assistant Professor, Department of Community and Health Systems, Indiana University School of Nursing, 1111 Middle Drive, W 421; Indianapolis, Indiana 46202, Office: 317-274-4439;

Email: jembree8@iu.edu

Kurt G Ellis, Vice President, Health System Operations, Columbus Regional Health; 2400 East 17 $7^{\text {th }}$ Street; Columbus, IN, 47203; Email: kellis@crh.org

Corresponding Author: Rebecca J. Bartlett Ellis, PhD, RN,_Assistant Professor, Indiana University School of Nursing, Indianapolis, IN; 1111 Middle Drive, E423, Indianapolis, IN 46202, Phone: 317-274-0047, Fax: 317-278-2021, Email: ribartle@iu.edu

This is the author's manuscript of the article published in final edited form as: Bartlett Ellis, R. J., Embree, J. L., \& Ellis, K. G. (2015). A Business Case Framework for Planning Clinical Nurse Specialist-Led Interventions. Clinical Nurse Specialist CNS, 29(6), 338-347. http://doi.org/10.1097/NUR.0000000000000162 


\section{A Business Case Framework for Planning Clinical Nurse Specialist-led Interventions}

More than 800 billion dollars are spent caring for people admitted to US hospitals annually; ${ }^{1}$ however, estimates suggest that $30 \%$ of medical spending is wasteful, unnecessary, and does not add care value. ${ }^{2}$ Inconsistent evidence exists that spending more on healthcare improves care quality, ${ }^{3,4}$ and in the few studies that do suggest relationships between cost and higher quality, clinical significance is modest $^{4}$. As of 2012, healthcare expenditure in the US accounted for almost $18 \%$ of the gross domestic product (GDP). ${ }^{5}$ Almost $20 \%$ of government spending is on healthcare. ${ }^{5}$

Costly hospital stays as well as the Value-Based Purchasing (VBP) program under the Affordable Care Act have led healthcare executives to focus on value in delivering high quality healthcare. Value is defined as healthcare-related outcomes (results) per unit of cost, ${ }^{6}$ and thus when quality is improved for the same cost, value rises. VBP pays participating hospitals for their acute care inpatient services based on the quality of care provided. ${ }^{6}$ Implementing evidence-based practice (EBP) interventions to improve quality requires using organizational resources, which are associated with costs. To remain competitive in the value-based healthcare market, healthcare organizations must implement EBP, decrease harm to patients, and reduce ineffective care.

The purpose of a business case is to justify the use of the organizational resources $^{7,8}$ ENREF 7 needed to implement EBP interventions or projects. Both EBP and the business case are approaches that integrate the best evidence that is informed by customers' needs, preferences, and values in decision-making. ${ }^{9}$ The difference between EBP and the business case is that the business case more formally focuses on resource use and total costs while ensuring that the intervention implementation supports the organization's vision and mission and adds value. The business case justifies the need to intervene to healthcare decision-makers. In the business case presented within this article, we focus on justifying the need for intervention based on the value proposition. We believe this approach more formally 
represents the future direction of healthcare as we move from fee-for-service to value based care.

Clinical Nurse Specialists (CNSs) are key to ensuring high quality patient care and thus to the financial success of any healthcare institution. Stabilizing health care costs and reducing waste are keys to an organization's success, ${ }^{10}$ and CNSs are in the perfect position to improve care quality by designing interventions that both improve patient outcomes and minimize healthcare system costs. To increase quality and lower cost, CNSs must incorporate basic business skills in their work. Skills that help build a "business case" for employing CNSs in any institution include planning, implementing, and evaluating evidence-based interventions.

The purpose of this paper is to describe the process of using a business case framework to plan for CNS work. Moving to value-based care delivery requires all healthcare professionals to operate differently. This requires CNSs to be mindful about developing interventions that will add value to the organization and patient care delivery during intervention planning, implementation and evaluation stages. This requires a focus on outcomes and efficiency in delivering care. Several different analyses are used to guide intervention planning to assure interventions are well-planned and adding value to the organization. Throughout this article, we use a case scenario as an exemplar of the many analyses that can be used to develop the business case.

The business case framework is designed to assist the CNS perform a series of analyses while considering the need for intervention, to develop interventions and explore the resource use and value added to the organization. While business cases have been used in other fields, using these analyses and justifying interventions using a business case framework in nursing care is unique. Healthcare is rapidly shifting from fee-for-service models to value based models and CNSs will need to be positioned to continue to be leaders in driving quality patient outcomes. This requires that faculty, students and practicing CNSs be prepared to address this shift and develop business skills that justify developing interventions. We believe 
this business case framework is a starting point to begin developing these skills and methods to formally document planning, implementation, and evaluation of interventions. Considerable evidence supports using EBP can reduce ineffective care, yet to date, estimating resource expenditure for intervention planning, implementation and evaluation is limited. Currently, there is not a systematic way for CNSs to document resource utilization and the full planning, implementation and evaluation processes in intervention delivery and this kind of documentation is very much needed.

The framework described in this article was developed by the CNS faculty at our school to help students develop business skills that provide a framework for intervention development. This framework can be used as a project-planning tool for CNS students and for practicing CNSs to make business cases for an intervention consistent with the organization's mission, vision, and strategic priorities. The business case, as we describe, is a framework that can guide intervention planning, focused on resource utilization and value-added care, in implementing interventions, which can serve as a basis for CNSs to begin documenting valuebased outcomes.

\section{Theory, Research and Practice}

The value-based care model informs the business case framework we describe. For healthcare organizations to achieve their stated mission and financial goals, quality outcomes must be achieved. Achieving quality outcomes will be a critical driver in value-based care. Furthermore, minimizing costs while achieving outcomes is desirable. Also informing the framework is the theory of corporate social responsibility (CSR), which speaks to organizations' legal and moral obligations. The legal obligation is to be financially responsible and the moral obligation is to interact ethically with the communities they serve. Providing EBP in light of making framed business decisions can assist the organization to provide value in delivery of healthcare services. There is also a responsibility of the organization to maintain viability as a 
business, whether the organization is for-profit or not-for-profit, and to provide for the welfare of its community. ${ }^{11}$

As decisions are made about patient care improvement projects, CNSs need to consider the problem, the context, and the resources needed to effectively intervene. The relative costs to the organization of intervening, or failing to intervene, must be determined.

A business case includes all of the considerations necessary to make decisions about important CNS-led interventions that can improve patient care. However, decisions in hospital management must also include how proposed actions affect costs and revenue. The business case answers difficult questions about allocation of limited resources ${ }^{12}$ and should also project a reasonable timeframe for financial or other return on an investment, that is of value in achieving quality outcomes. Table 1. includes key business terminology the CNS may encounter in practice.

\section{Tenets of the Business Case Framework}

Healthcare leaders utilize business cases to ensure that their organizations receive a return on investment resulting from financial expenditure. An extensive business case provides key information about critical factors influencing the likelihood of achieving desired outcomes. This information permits leaders to make well-informed, financially sound decisions about projects that have a high likelihood of improving quality of care and patient outcomes. ${ }^{6,13}$ ENREF 6 The business case includes additional analysis tools beyond the traditional cost-benefit analysis. The business case we present is designed to document the planning, implementation and evaluation of interventions as a way to justify the cost of resources used in CNS led interventions. This is important so CNSs can be positioned to document care outcomes while focusing on the efficiency of resources that are utilized in interventions. This can serve as a basis for further intervention refinement and justification to decision-makers the contribution of nursing and CNSs. A business case links factors imperative to change and serves as a framework for planning. Six tenets of our business case are: 
1. Organizational values, vision, mission, and strategic goals guide decision-making.

2. Process design is guided by thoughtful engagement of key stakeholders and process owners, both internal and external, including patients.

3. Understanding the internal and external environment as reflected by customers' needs, forecasting, and competitive markets that effectively operate and sustain a healthcare organization (business) is important.

4. Financial impact of operational changes, including implementation cost, return on investment, cost benefit/avoidance, and actual costs are considered in decision-making.

5. Anticipated outcome(s) from implementing change are inextricably linked with strategic priorities and measurement strategies and are determined prior to making the change.

6. Patient outcomes (health, safety, quality, and cost) afforded by change should outweigh the outcomes of not changing (health, safety, quality, and cost).

Using these tenets as a guide, we developed the business case framework to guide our students' intervention projects. We developed this framework because this is a unique approach to addressing value-based care, combining several analyses and tools already in existence. With this approach we combine both business practice with value-based care. Using this framework, our students have developed, for example, a pain management nursing education program to increase HCAHPS scores on pain control measures; a stage-based intervention to maximize readiness for bariatric surgery and efficiency in the review of cases before surgery; and a stroke survivor and caregiver education intervention to reduce 30-day re-admission rates to the hospital.

\section{Business Case Framework}

The business case framework (Figure 1.) consists of a series of analyses that guides the CNS to explore the need for interventions, determine how best to develop the organizationspecific intervention, and explore the associated costs of intervention implementation. As the 
CNS and team develop the business case, they will document their findings and work, which will serve as the completed business case, See Appendix A.

\section{Business Case Overview}

Initially, a needs assessment (NA) must be conducted to fully understand the need and the extent to which intervention is necessary. The need should be clearly defined in terms of the patient population, the significance of the problem, and the overall impact of the problem. Once the need is established and the intervention is deemed to be aligned with organizational values and priorities, a team is formed. The CNS and planning team that consists of stakeholders undertakes a critical appraisal of available evidence. The intervention plan is developed and costs associated with the intervention are estimated, including resource use and outcome costs.

\section{Needs Assessment}

NA is a systematic process to identify discrepancies between the current state and the desired state of a situation. The need for intervention can be triggered from a variety of sources, including clinical problems, internal and external benchmark data, regulatory guidelines and recommendations, and new research. In our course, we use the NA to understand the needs of patients, healthcare providers, and the organization in developing interventions to help achieve a desired health outcome. The first two steps of our business case NA focus on gathering evidence from diverse sources to clearly identify the need to develop interventions. These steps include a 1) stakeholder analysis and 2) a market analysis.

Case Scenario

The CNS notes that Hospital Consumer Assessment of Healthcare Providers and Systems (HCAHPS) scores on questions about understanding medications after discharge are lower than the targeted benchmark and have decreased over time. The CNS recognizes that these lower scores are associated with potential loss in Medicare reimbursement and, more importantly, that they indicate the desired quality of care is not being met. These data are publicly reported and available for consumers, who may choose where to receive care based on 
these data. Concerned, the CNS first looks at current practice to assess for variation and then conducts a needs assessment.

For a solution, the CNS selects the best evidence from the literature combined with the preferences and needs of patients served by the organization. The CNS starts with the market analysis. Enlisting assistance from stakeholders, the CNS acquires market research data used by the organization (e.g., consulting services used by the hospital, state department of health data, the Dartmouth Atlas of Health Care, Centers for Medicare and Medicaid Services, professional organizations). The CNS assembles a team and the team answers the market analysis questions. Additionally, to solicit the voice of the customer directly, the CNS/team interviews patients at the time of hospital discharge and conducts follow-up phone calls after discharge to better understand factors affecting patients' understanding of their medications. The team learns that the written instructions provided to patients are confusing to follow once they have been discharged home.

Research evidence suggests that as many as $20 \%$ of patients experience adverse drug events that may be preventable. ${ }^{14}$ This hospital discharges 7,300 patients per year on average. Based on the research evidence, as many as 1,460 patients could be at risk of experiencing an adverse drug event after hospitalization. The market data and hospital data identify that two hospital readmissions in 2012 were related to medication and/or drug poisoning. The mean cost of readmission for medication or drug-related poisoning is $\$ 9,505$ for all payers. ${ }^{15}$ This figure for readmissions would represent those who took too much medication and who were then readmitted to the hospital. Not included in this figure is the cost associated with omission of medication. For example, a patient who does not take a blood thinner medication and then experiences a stroke would not be included in this value. This is a rough estimate of value based on available data.

Stakeholders are identified and invited to participate as members of the interdisciplinary team involved in developing the intervention and business case. The team begins by reviewing 
available data and research literature. This information helps the team understand the problem and potential interventions.

\section{Stakeholder Analysis}

The stakeholder analysis assists the CNS to identify all of the potential individuals who can inform the project, including patients, healthcare providers, and the organization. Representatives of these stakeholders can comprise the team that will develop the business case. Developing a table to identify key departments, systems, and community interests, as shown in Table 2, is useful to identify key individuals who can inform the business case analyses. For more in-depth details about the needs assessment and stakeholder analysis see Witikin \& Altschuld, $1999 .{ }^{16}$

\section{Market Analysis}

Although the market analysis may not be an analysis often considered when planning nursing interventions, it is incredibly important in today's healthcare market place. Efforts to make healthcare costs and quality metrics transparent, publicly available, and easily accessible on the Internet help patients make informed choices on where to seek healthcare. For example, the Centers for Medicare and Medicaid Services ${ }^{17}$ ENREF 9 permit patients to compare hospitals' quality measures against one another (www.medicare.gov/hospitalcompare). In a publication to guide patients on selecting where to receive their care, CMS suggests that, if care is non-emergent, patients should consider going to hospitals that do a better job taking care of patients with similar needs. ${ }^{18}$ Thus, just being the local and closest hospital may not be the main attraction for patients in the future. Patients will be looking at competitors when selecting where to receive care, and therefore CNSs should be looking at the competitive market too.

The level of detail in the market analysis depends on the intervention. If the intervention involves starting a new service (e.g., support group), it may be appropriate to focus on organizations in the same market share area. However, if the intervention is more local and 
internal to the organization, the emphasis is placed on similar services already available in the institution. Market analysis answers the following questions:

- How many people does the current process in the market area affect?

- What are the strengths, weaknesses, opportunities, and threats facing our institution and surrounding institutions?

- What similar services or processes currently exist for our patients?

- Have similar interventions been used by our patients or competitors?

- What are the current or future regulations that affect this patient population (accreditation, government, reimbursement)?

- What outside influences may impact the practice change?

For more in-depth understanding of a competitive markets and value in care consult Prahalad \& Ramaswamy, 2013. ${ }^{19}$

Data, such as patient care quality indicators can assist in prioritizing needs for different service populations and communities. For example, data from external sources can help plan for the needed capacity of services related to incidence and prevalence of a disease or syndrome in a specific area. ${ }^{20}$ Evaluating the mix of services required and/or desired for a syndrome or disease can help prioritize needs of populations and communities. ${ }^{20}$ The market analysis is helpful in understanding the standard of practice and coordination of services in a healthcare delivery system. ${ }^{20}$ In order to continuously improve clinical care, the CNS must analyze the current and desired future state of clinical nursing care.

Organization Strategic Priority linked with problem. Once the need for intervention is identified, the CNS should determine if intervening fits with the organization's vision, mission, and strategic goals. Developing a table that outlines the links between organizational priorities and the opportunity for intervention can be helpful to include in the business case and serves as a visual for the connections. See Figure 2 for an example aligned with our scenario. 
Team Formation and Goal Setting. To begin developing the business case, the CNS will build an interdisciplinary team, which will set goals and objectives for the project and ensure that it is aligned with strategic priorities of the organization. Following an EBP model, the team will critique and synthesize research for use in practice and determine if there is sufficient research evidence to proceed with the intervention.

\section{Intervention Plan}

By reviewing the evidence gathered up to this point and based on stakeholder input, the CNS and interdisciplinary team should develop the intervention implementation plan as follows: Explain the plan's objectives in clear quantifiable terms.

- Align the objectives with strategic priorities.

- Describe the time frame to complete the objectives.

- $\quad$ Outline how the plan's objectives may be implemented and are advantageous

- Present steps to achieve the objectives.

- Describe the specific activities of the intervention.

Once the objectives, time frame, and steps are outlined, the CNS can begin to evaluate the finances involved in the intervention.

\section{Decision Analysis}

Deciding on the appropriate intervention should be well grounded in evidence and perceived by stakeholders as having value. Several different intervention options may be identified requiring the team to make selective decisions about the best intervention. When presenting the business case, the team will describe potential options, such as maintaining current practice, but make recommendation for one intervention. Consideration of options requires some thought about resource utilization for various interventions, the potential effects of interventions on outcomes, and anticipated outcomes and unintended consequences. Stakeholder input assists in setting priorities and allocating resources. ${ }^{21,22}$ The team should 
keep these factors in mind while conducting the financial analysis, which is why it is critical to involve stakeholders in this work.

\section{Financial Analysis}

Financial analysis is extremely complex and, given the current healthcare climate, we are likely to see new economic models based on value in healthcare. In a value-based model, costs associated with care required to achieve desired outcomes must be measured. Current efforts have focused on quality outcomes. However the costs to delivery the care to achieve those quality outcomes have received less attention. All relevant costs of resources should be considered, including administrative, clinical personnel, supplies, equipment, and the physical space required to deliver high quality care. ${ }^{23}$ To estimate the cost of resource utilization in developing interventions we use the time-driven activity-based costing (TDABC) model, which focuses on tracking the resources used per activity. ${ }^{24}$ There are several different economic approaches to cost estimation the CNS may be exposed to in addition to the TDABC approach (See Table 3).

To calculate costs, all activities associated with planning and piloting the intervention in practice, such as the number of team meetings leading up to implementation should be identified. Then the resources involved with these activities, including job titles of human resources personnel involved as well as any equipment, medical supplies, and/or office supplies can be identified. When available, the human resources and finance department provide these dollar amounts or they are estimated based on hourly and wage values for the market area available on the Internet. Costs associated with each resource for each activity should be determined relative to the intervention. Time spent on various activities in actually delivering an intervention in practice can be studied during the pilot-testing phase.

The following types of questions can guide the CNS to determine resource use.

- Current technologies and capabilities, including their strengths and areas of needed support 
- Facilities evaluation/space requirements

- Utilization

o impact on core service areas, ancillary areas, and other departments and services

o current and potential referral sources

o related support structure of the institution

o current service delivery/operation structures and consideration for suppliers' potential price increases or discontinuation of a product

- Number of full-time or part-time staff needed to support program and capability to retrain existing staff or hire new staff

The cost of certain quality outcomes can be derived from the Healthcare Cost and Utilization Project (HCUP), which provides statewide data from individual hospitals (http://hcupnet.ahrq.gov/HCUPnet). The HCUP provides healthcare-related data including allpayer discharge level information for the United States. ${ }^{25}$ Consulting the finance department for hospital-specific data may provide more relevant hospital-specific values. The type of payer will also influence this dollar amount, and this level of detail may be available in the CNS's organization. Consulting the finance department, or including a finance department member on the planning team, can help gain access to these types of data and should be considered.

All interventions have associated expenses; the key to performing the analysis is to find the best intervention to achieve desired outcomes with the most efficient use of resource expenditure. There is a certain amount of uncertainty when no prior data or predictive models exist. Individual patient differences and how differences may affect outcomes cannot always be anticipated, and more health economic research is needed to fully understand the economic implications of intervention development. ${ }^{26}$ Furthermore, the best interventions are not always the most cost effective. Despite these limitations, the financial analysis is integral to intervention planning. 
Acquiring a detailed understanding of the financial impact of nursing interventions for patient care costs is critical for CNSs. ${ }^{27}$ Healthcare reform efforts will lead to better understanding of healthcare costs, and CNSs need to be prepared. By starting to analyze the costs of interventions, CNSs can help shape cost-effective quality outcomes, rather than face top-down mandates that solely focus on reducing costs.

Returning to our scenario, in order to address the problem, the team formulates project goals and objectives that are aligned with the organization's vision, mission, and strategic priorities. The team then discusses the research literature in light of the market data and begins development of the intervention plan and writing up the business case. At this point the team can draft a description of the problem and the goals and objectives related to the project. This helps guide their review of evidence. Evidence suggests that follow-up phone calls specific to medications when made by pharmacists may be effective. ${ }^{28}$ Interventions using RNs involved bedside nurses, who were unable to keep up with the volume of post-discharge calls. ${ }^{28}$ Followup phone calls for medication management may be effective, especially when done with protected time to call patients. The team discusses intervention opportunities and prioritizes interventions considering resource utilization.

The team starts to make a list of the activities involved with intervention planning, implementation and evaluation. This list will then be used to develop the financial assumptions that will be used in the business case.

Activities and data associated with Intervention:

Team activities

- Team meetings:

o Review data and research findings

o Develop intervention process plan

o Identify staff who could call patients using stakeholder input

o Meet with unit managers to identify opportunities. 
o Develop business case

o Review business case

o Present to leadership

Intervention Deployment Activities:

- Discharge summaries with medication lists will be placed in a designated location to trigger follow-up calls.

- Develop semi-structured script to guide the phone call

- Educate staff who will deliver the intervention

- Present information at unit staff meetings

- Send emails

- Monitor and evaluate after pilot intervention

Assumptions developed by the team:

- Follow-up calls will be made 7 days per week in order to meet the goals of the project

- Staff must be able to answer questions about medications and assess information, so requires either a registered nurse or pharmacist to make the calls.

- Based on hospital data, on average 20 patients are discharged from inpatient care daily.

- Follow-up phone calls are estimated at 15 minutes per call

- Based on above assumptions, this intervention will require 5 hours of nursing/staff time per day.

- Team meetings are 1 hour in duration. Human Resources associated with the team for 1 hour is equal to $\$ 1,000.00$ (based on members and salaries).

- Need dedicated space to call patients, capable of protecting patient privacy.

Financial Assumptions used to develop business case 
Intervention Deployment

Expenses

\begin{tabular}{lcccc|c}
\hline & & & \multicolumn{1}{c}{$\begin{array}{c}\text { Total Compensation } \\
\text { (Direct compensation }\end{array}$} \\
Staff Positions & Number & Hourly Rate & Worked Hours & FTEs & and benefits) \\
\hline RN & 2 & $\$ 33.00$ & 35.00 & 1.20 & $\$ 78,078$
\end{tabular}

Intervention Planning Costs (abbreviated)

Activity

Number of

Resources meetings Expenses

\begin{tabular}{llll}
\hline Team meetings & & & \\
\hline Review data and research findings & Team & 5 & $\$ 3,000.00$ \\
\hline Develop intervention process plan & CNS & & \\
\hline Identify staff who could call patients & & 2 & $\$ 500.00$ \\
using stakeholder input & Team & 1 & $\$ 1,000.00$ \\
\hline Meet with unit managers to identify & Team & 1 & $\$ 1,000.00$ \\
opportunities. & Management & 2 & $\$ 2,000.00$ \\
\hline Develop business case & Team & 2 & $\$ 2,000.00$ \\
\hline Review business case & Team & 1 & $\$ 1,000.00$ \\
\hline Present to leadership & Team & & $\$ 12,500.00$
\end{tabular}

\section{Implementation Plan}

A business case also requires an implementation plan. This plan describes how the intervention will be placed into action and tracked over time. ${ }^{29}$ The implementation plan focuses on the outcomes as well as evaluating the processes and structures required to implement the intervention. Outcomes can be evaluated based on three spheres of influence: the patient, the 
nurse, and the system. Key metrics for evaluation, most likely were identified in the NA, but additional key metrics may exist. Referring to the organizational strategic plan may be helpful to select key metrics. Additional metrics that are specific to the implementation of the intervention may also guide evaluation.

Considerations for intervention evaluation include:

Implementation:

- Assign responsibility for each implementation step.

- Describe the "key success factors" impacting the implementation

- . Develop a time line, including project milestones for meeting the plan's objectives.

\section{Monitoring:}

- Describe the key variables monitored

- Targeted quality outcomes

- Patient and family satisfaction

- Resource utilization

- Time-driven activity-based costing

- Impact on other services in organization

- Describe the process and frequency for monitoring/reporting in relation to the objectives

- List report responsibility

Following along with our scenario, the CNS and intervention planning team developed the following implementation plan elements. The team identified the activities associated with implementing the intervention. This includes the resources involved and the anticipated time. Using this information and the financial analysis components can be used to develop the expenses associated with each of the activities.

Implementation Plan used to develop business case 


\begin{tabular}{|c|c|c|c|}
\hline \multirow[t]{2}{*}{ Activity } & \multicolumn{3}{|c|}{ Number of } \\
\hline & Resources & meetings & Expenses \\
\hline Discharge summaries with medication & & 3 & \\
\hline lists will be placed in a designated & Discharge & & \\
\hline location to trigger follow up calls. & Nurse & & $\$ 3,000.00$ \\
\hline Develop semi-structured follow-up call & & 5 & \\
\hline script & CNS & & $\$ 500.00$ \\
\hline \multicolumn{4}{|l|}{ Educate staff who will deliver the } \\
\hline intervention & CNS & 2 & $\$ 2,000.00$ \\
\hline Present information at unit staff & & 1 & $\$ 1,000.00$ \\
\hline meetings & CNS & 1 & $\$ 1,000.00$ \\
\hline Send emails & CNS & 2 & $\$ 2,000.00$ \\
\hline \multicolumn{4}{|l|}{ Monitor and evaluate after pilot } \\
\hline intervention & Team & 2 & $\$ 2,000.00$ \\
\hline
\end{tabular}

Additional supplies needed and associated decisions:

Extra paper for printing discharge summaries or develop an electronic report

Telephone service

Desk

Computer

Office space

Support systems involved: Informatics, purchasing department, distribution services, nursing services.

Critical Review of Business Case Elements 
Once all of the above steps are completed, the CNS and intervention planning team need to complete a critical review of their business case. The business case should clearly support the organization's vision, mission, and goals while addressing a clinically relevant unmet need either at the patient or community level. Ensure the business case clearly demonstrates efficient use of resources while adding value to patient care needs. Additionally, make sure that any necessary regulatory approvals and requirements are met in the design of the intervention, if necessary. The most important component of making the business case is that in addressing the above components there is a clear demonstration for return on investment that adds value. While the return on investment might also lead to increased revenue, it is important that the intervention is value added. Value means that the total costs to deliver an intervention should be considered in light of the actual outcomes. ${ }^{23}$ Articulating the value of the intervention is critical. Moving in to a value-based healthcare model requires CNSs to continue to improve outcomes while driving the costs to deliver the interventions down. One foreseeable way to accomplish this is to actually track costs while planning, implementing and evaluating outcomes and that is the basis of making a business case. The business case justifies the use of resources in delivering an intervention and then can serve as a basis for future improvement work to continue to improve the value-added care.

In our scenario, the CNS-led team efficiently developed an intervention to support patients' medication taking by using follow up phone calls. In doing so, they also efficiently used hospital resources through a return to work program. This intervention aligned with the organization's vision, mission and goals and helped meet two unmet needs related 1) supporting patients with medications and 2) helping employees return to work and contribute to delivering a previously unmet need. While there are initial start-up costs, because of the nature of the problem, the organization will experience a return on investment. Most importantly though, there is clear value added to organization, staff, and patients by developing this intervention. 
The actual documentation of the business case can be a formal written report or a verbal presentation to leadership. We recommend developing reports because they can then be used to formally document and demonstrate CNS outcomes. Appendix A demonstrates an example of a simple written business case following our scenario used in this article. This document can serve as a template and be adapted for individual organizational use.

\section{Conclusion}

CNSs are uniquely positioned to lead intervention planning, implementation, and evaluation. By developing business skills, the CNS will be better positioned to make the business case for clinical interventions. Clinical nurse specialists can positively influence healthcare by adopting and using the best available business tools and empirical evidence to implement interventions that promote high quality and cost-effective care. This business case framework provides a model for intervention planning to meet fiscal and clinical targets and then assists in intervention development and execution.

\section{Implications for CNS Practice}

Healthcare systems seek changes that provide quality at a reduced cost, and assessing and evaluating the business implications of nursing interventions is exceedingly important. Clinical nurse specialists need business skill development. Using a business case framework is one way to develop the needed skills, and the framework described in this paper can assist the CNS to present a strong case for intervention adoption by clearly identifying needs, gaining stakeholder support, delineating cost, and presenting the quality metrics to improve financial reimbursement. Gaining support from healthcare administration requires that interventions be aligned with the mission and strategic priorities of the organization. By using this business framework, CNSs can begin to demonstrate to hospital leaders how their clinical skills informed by business practices can positively affect the organization's overall goals. 


\section{Figure Legend}

Figure 1. Business Case Framework

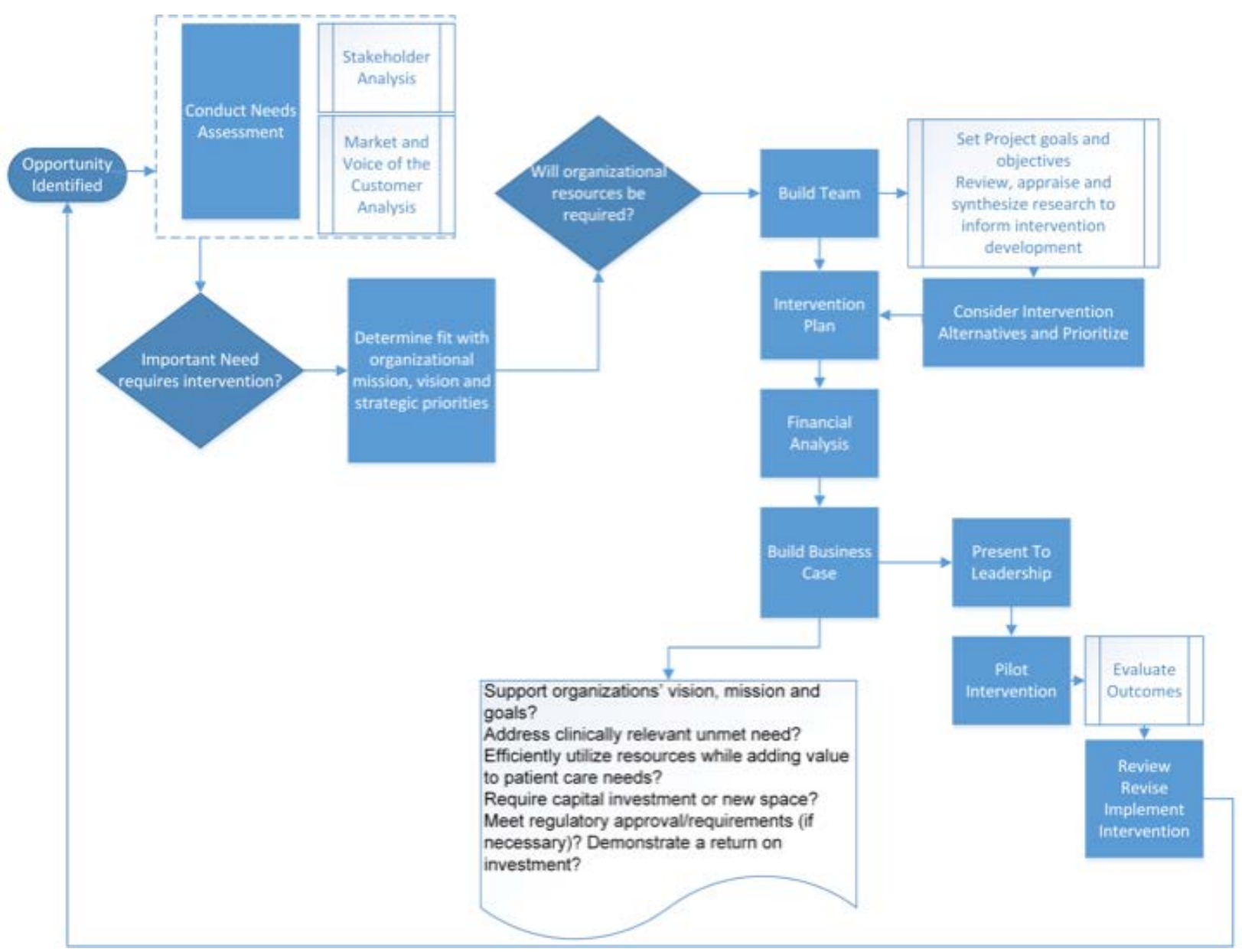


Figure 2. Aligning Intervention Opportunity with Organizational Mission, Priorities and Outcome Evaluation

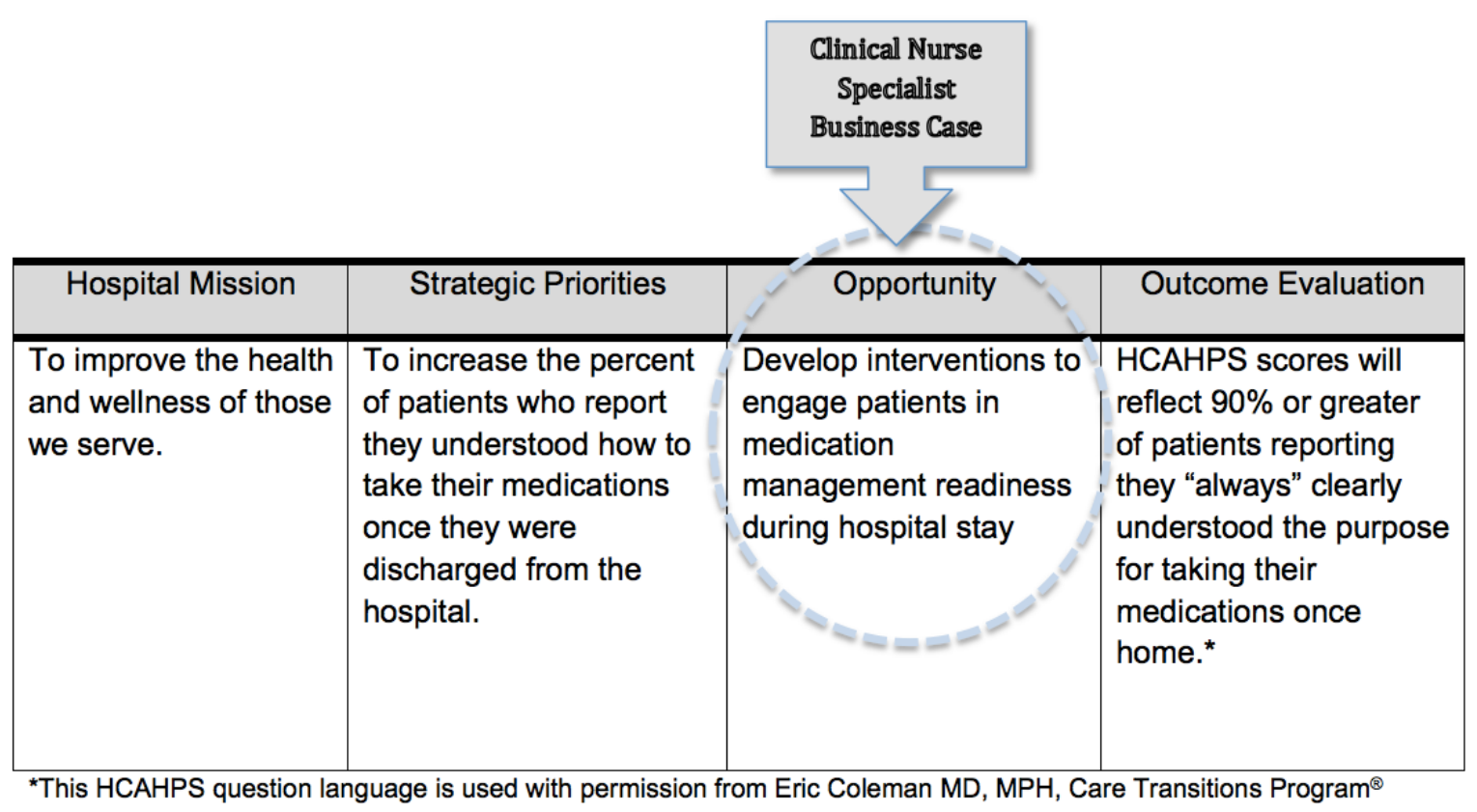


Table 1. Common Business Terminology

Forecasting - an evidence based approach to model
and predict future financial outcomes. Typically
involves historical data to build predictive models to
help make decisions about the future.
Competitive market - other healthcare services or
organizations that may be competing with each other
to meet healthcare consumer needs for the same
consumers.
provided or goods sold.
investing resources (people, money, etc.)
time.
(equipment and building) that are depreciated across
department.
labor to a project.
Indirect Costs -costs of "doing" business that may not
be directly associated with a project (e.g.


Table 2. Stakeholder Analysis Planning Table

\begin{tabular}{|c|c|c|}
\hline Unit/Department & Organization/System & Community \\
\hline $\begin{array}{l}\text { Pharmacy } \\
\text { - Director } \\
\text { - Unit Pharmacist }\end{array}$ & $\begin{array}{l}\text { Hospital Based } \\
\text { - } \quad \text { Service Line Director } \\
\text { or Vice President }\end{array}$ & $\begin{array}{l}\text { Patients } \\
\text { - Community Advisory } \\
\text { Board Member }\end{array}$ \\
\hline $\begin{array}{l}\text { Nursing Medical Units } \\
\text { - } \text { Manager } \\
\text { - Nurse Practice } \\
\text { Council } \\
\text { Representative }\end{array}$ & $\begin{array}{l}\text { Electronic Medical Record } \\
\text { Vendor } \\
\text { Chief Nurse Officer }\end{array}$ & \\
\hline $\begin{array}{l}\text { Information Technology } \\
\text { - Chief Information } \\
\text { Officer } \\
\text { - System Analyst }\end{array}$ & $\begin{array}{l}\text { Finance Department } \\
\text { - Chief Financial Officer }\end{array}$ & \\
\hline
\end{tabular}

Table 3. Common Cost Analysis Approaches

\begin{tabular}{|l|l|}
\hline \multicolumn{2}{|l|}{ Common Cost Analysis Approaches } \\
\hline Cost-benefit analysis (CBA) & Identify direct and indirect costs \\
& $\begin{array}{l}\text { Identify all direct and indirect costs of the positive } \\
\text { outcome }\end{array}$ \\
\hline
\end{tabular}




\begin{tabular}{|l|l|}
\hline & $\begin{array}{l}\text { Focused on costs associated with implementing one } \\
\text { intervention }\end{array}$ \\
\hline Cost-effectiveness analysis $^{31}$ & $\begin{array}{l}\text { Similar features of CBA and compares costs of } \\
\text { implementing one or more interventions against the } \\
\text { cost of a comparison }\end{array}$ \\
\hline Cost-avoidance analysis (CAA) & $\begin{array}{l}\text { Identifies only the costs avoided from implementing the } \\
\text { intervention }\end{array}$ \\
\hline
\end{tabular}


Appendix A. Business Case. The data and dollar amounts contained within were designed for this specific example and should not be used for intervention planning.

Improving Patient's Understanding of Medications Following Discharge: A Follow-up Phone Call Intervention

Executive Summary

Implementation of a Registered Nurse follow-up phone call within 48 hours of discharge will

1. Enhance patients' understanding of their medications,

2. Allow for patient assessment of medication-related problems to prevent adverse events or re-hospitalization; and

3. Facilitate RN transition to work from short-term/long-term disability.

- $\quad$ Program Start-up costs $=\$ 102,078$

- $\quad$ Annual Cost for Program $=\$ 100,000$

- $\quad$ Annual Patient-level Cost Savings $=\$ 749,010$

- Annual RN Transition program Savings $=\$ 104,000$

\section{Background Information}

- The organization's mission is to be the provider of choice for the community that we serve, and one strategic priority for the organization is to meet or exceed HCAHPS national benchmarks.

- Medication management after hospital discharge is one task we strive to prepare our patients for as they transition to home.

- Medication management requires that patients understand the purpose and side effects of their medications and possess the skills and behaviors to act on that understanding to take medications as prescribed. ${ }^{32}$ 
- Though patients may state at the time of discharge that they understand how to take their medications, actual understanding of how to take their medications at home is a challenge for our patients, based on our review of the literature, stakeholder analysis, and voice of the customer.

- HCAHPS hospital-level scores indicated $51 \%$ of patients reported they strongly agreed (known as topbox scores) that they understood their medications at discharge.

- Confusion about how to take their medications exists when patients arrive at home

o Patients' medication management can be particularly complicated as they transition from hospitalization to post-discharge settings.

o At discharge our patients are prescribed at least one medication and more than $20 \%$ take five or more ${ }^{33}$

o During hospitalization, multiple medication changes can occur including the addition of new medications or deletion of old ones.

- Such changes can lead to misunderstanding and difficulty in medication management following hospitalization, increasing patients' risk for adverse drug events. ${ }^{34}$

o Research evidence suggests as many as $20 \%$ of patients experience adverse drug events that may be preventable. ${ }^{14}$

- Based on our hospital-level data, as many as 1,460 patients could be at risk of experiencing an adverse drug event after hospitalization.

o Costs associated with adverse drug events can exceed $\$ 730,000$ annually, conservatively

o At least 2 patients were re-hospitalized in our hospital for medication and/or drug poisoning, with costs estimated at $19,010^{15}$ 
The organization has been evaluating the possibility of a return-to-work health promotion program for hospital staff returning to work after disability leaves.

- Work health promotion programs can enhance recruitment and retention, absenteeism, disability rates, and enhance worker productivity. ${ }^{35}$

- An average of $40 \mathrm{RNs}$ annually would qualify for such a program

- Cost savings of such a program would be approximately $\$ 2,600$ per employee ${ }^{35}$

- Currently no return-to-work program exists for RNs

\section{Alternatives Considered}

1. Discharge follow-up phone calls by licensed clinicians (registered nurses or pharmacists)

o Follow-up phone calls permit licensed caregivers to connect with patients without the added time for transportation either by the care provider or patient.

o Requires 1.2 FTEs

- Using existing licensed staff and adding on to their patient care responsibilities can increase harm to patients already in their direct care, and therefore we will not use these resources. ${ }^{28}$

- Stakeholders recommended using flex staff when hospital acuity requires staff reductions and/or using staff on short-term disability in a return-towork program.

2. Home health visits after discharge

o Requires increased FTEs to home health staff

o Would require time and travel to approximately 20 additional patients each day.

- Requires licensed clinical staff: RN or pharmacist

3. Medication review by pharmacist prior to discharge

o Allows licensed pharmacist to meet with each patient prior to discharge 
o Requires 1.2 FTEs

o Allows for patient assessment prior to discharge

o Patients currently state they understand their lists but once they actually get home and try to manage medications in their home environment they have difficulty

\section{Recommendations}

- This intervention consists of follow-up phone calls made to all patients within 2 days of discharge from the hospital through a return-to-work health program for Registered Nurses.

- This intervention will add value by improving patient outcomes with regard to medications while also supporting the hospital workforce.

- The purpose of the phone call is to ensure that patients understand their medications and allows patients to ask questions about their medications.

- This intervention plan's objective is to improve patients' understanding of their medications after discharge as measured by HCAHPS scores. The current score is $51 \%$ in the topbox and the goal is to increase topbox ratings to benchmark within one year.

- The net savings associated with piloting this intervention for the first year is estimated at $\$ 650,932$. 


\section{References}

1. Forum H. Fast facts on US hospitals. 2014; http://www.aha.org/research/rc/stat-studies/fastfacts.shtml. Accessed October 28, 2014, 2014.

2. Wennberg JE, Fisher E, Sharp S, McAndrew M, Bronner K. The care of patients with severe chronic illness: an online report on the Medicare program by the Dartmouth Atlas Project. Center for Evaluative Clinical Sciences, Dartmouth Medical School. Hanover, NH. 2006.

3. Hussey PS, Anderson GF, Osborn R, et al. How does the quality of care compare in five countries? Health Affairs. 2004;23(3):89-99.

4. Hussey PS, Wertheimer S, Mehrotra A. The Association Between Health Care Quality and CostA Systematic Review. Annals of internal medicine. 2013;158(1):27-34.

5. Organization WH. Unites States of America statistics summary (2002 - present). 2014; http://apps.who.int/gho/data/?theme=country\&vid=20800. Accessed January 8, 2015, 2015.

6. Porter ME, Teisberg EO. Redefining health care: creating value-based competition on results: Harvard Business Press; 2006.

7. Needleman J, Buerhaus PI, Stewart M, Zelevinsky K, Mattke S. Nurse staffing in hospitals: Is there a business case for quality? Health Affairs. 2006;25(1):204-211.

8. Carroll AB, Shabana KM. The business case for corporate social responsibility: a review of concepts, research and practice. International Journal of Management Reviews. 2010;12(1):85105.

9. Titler MG, Kleiber C, Steelman VJ, et al. The lowa Model of Evidence-Based Practice to Promote Quality Care. Critical care nursing clinics of North America. 2001;13(4):497-509.

10. Berwick DM, Hackbarth AD. Eliminating waste in US health care. JAMA. 2012;307(14):15131516.

11. Brusseau J. Chapter 1 What is business ethics? The business ethics workshop, v. 1.0: Flat World Education, Inc. ; 2015.

12. Hadaway L, Wise M, Orr M, Bayless A, Dalton L, Guerin G. Making the Business Case for Infusion Teams: The Purpose, People, and Process. Journal of Infusion Nursing. 2014;37(5):321-346.

13. Gambles I. Making the business case: proposals that succeed for projects that work: Gower Publishing, Ltd.; 2009.

14. Kanaan AO, Donovan JL, Duchin NP, et al. Adverse drug events after hospital discharge in older adults: types, severity, and involvement of Beers Criteria Medications. Journal of the American Geriatrics Society. 2013;61(11):1894-1899.

15. Quality AfHRa. All patient readmissions within 30 days National statistics, 2012. 2012; http://hcupnet.ahrq.gov/HCUPnet/HCUPnet.jsp?ld=5451108F79C60657\&Form=DispTab\&JS=Y\& Action=Accept.

16. Altschuld JW, Witkin BR. From needs assessment to action: Transforming needs into solution strategies: Sage; 2000.

17. Services CgCfMM. Hospital value-based purchasing. 2014; http://www.cms.gov/Medicare/Quality-Initiatives-Patient-Assessment-Instruments/hospitalvalue-based-purchasing/index.html. Accessed January 7, 2015.

18. Services CfMaM. Guide to choosing a hospital. In: Services CfMaM, edn.d.

19. Prahalad CK, Ramaswamy V. The future of competition: Co-creating unique value with customers: Harvard Business Press; 2013.

20. Organization WH. Workbook 3-needs assessments. Evaluation of Psychoactive Substance Use Disorder Treatment. WHO/MSD/MSB 00.2 d. 2000;9:2010.

21. Gupta K. A practical guide to needs assessment: John Wiley \& Sons; 2011.

22. Witkin BR. Planning and conducting needs assessments: A practical guide: Sage; 1995. 
23. Kaplan RS, Porter ME. How to solve the cost crisis in health care. Harv Bus Rev. 2011;89(9):4652.

24. Udpa S. Activity-based costing for hospitals. Health care management review. 1996;21(3):83.

25. Quality AfHRa. What is HCUP? A brief description of HCUP and HCUP data. n.d.; http://hcupnet.ahrq.gov/HCUPnet.jsp? Id=482C03143BEF3A44\&Form=DispTab\&JS=Y\&Action=\% 3E\%3ENext\%3E\%3E\&What is HCUP. $x=1$.

26. Hill SR. Cost-effectiveness analysis for clinicians. BMC medicine. 2012;10(1):10.

27. Fisher ML, Blue L, Stark LD, Powers JM. Economic and Financial Considerations for Clinical Nurse Specialists. Foundations of Clinical Nurse Specialist Practice. 2014:319.

28. Bahr SJ, Solverson S, Schlidt A, Hack D, Smith JL, Ryan P. Integrated Literature Review of Postdischarge Telephone Calls. Western journal of nursing research. 2014;36(1):84-104.

29. Wholey JS, Hatry HP, Newcomer KE. Handbook of practical program evaluation. Vol 19: John Wiley \& Sons; 2010.

30. Sin $\mathrm{CH}, \mathrm{McMahon} \mathrm{A}$. Making the economic case for nursing innovations: horses for courses: Chih Hoong Sin and Ann McMahon describe seven approaches to conducting economic assessments and debunk some jargon along the way. Nursing Management. 2014;21(4):38-41.

31. Marceau L, McKinlay J, Piccolo R. Clinical vignettes in health services research: advantages and limitations of different formats: Orlando, FL: AcademyHealth; 2012.

32. Bailey SC, Oramasionwu CU, Wolf MS. Rethinking adherence: $A$ health literacy-informed model of medication self-management. Journal of health communication. 2013;18(sup1):20-30.

33. Zhong W, Maradit-Kremers H, St. Sauver J, et al. Age \& sex patterns of drug prescribing in a defined American population. Mayo Clinic Proceedings. 2013;88(7):697-707.

34. Dwamena F, Holmes-Rovner M, Gaulden CM, et al. Interventions for providers to promote a patient-centred approach in clinical consultations. Cochrane Database Syst Rev. 2012;12.

35. Serxner S, Gold D, Anderson D, Williams D. The impact of a worksite health promotion program on short-term disability usage. Journal of Occupational and Environmental Medicine. 2001;43(1):25-29. 
